\title{
Portrait of a Second-Grade Problem Poser
}

\author{
Mahati Kopparla 1, Mary Margaret Capraro 1,2* \\ ${ }^{1}$ Department of Teaching, Learning and Culture, Texas A\&M University, 4232 TAMU, College Stations, TX 77843- \\ 4232, USA \\ 1 Aggie STEM Education, Texas A\&M University, 4232 TAMU, College Station, TX 77843-4232, USA
}

*Corresponding Author: mmcapraro@tamu.edu

Citation: Kopparla, M. and Capraro, M. M. (2018). Portrait of a Second-Grade Problem Poser. European Journal of STEM Education, 3(2), 03. https://doi.org/10.20897/ ejsteme/2684

Published: August 8, 2018

\begin{abstract}
Although some students might struggle with problem posing, the positive effects on student learning and abilities may be far reaching for those who engage in this activity. Problem posing requires students to create their own problems rather than to solve problems posed by others. Problem posing is not regularly taught; however, reform proponent groups recognize problem posing as a strategy that should be integrated more routinely into mathematics classrooms. A single case study was conducted in conjunction with a larger quasiexperimental study in which mathematics education researchers worked with groups of $2^{\text {nd }}-5^{\text {th }}$ grade students twice a week over the course of a semester. For the single case study, two of the researchers randomly selected one second-grade student and examined the student's progress as she engaged in problem-posing activities during the semester. Based on the student's work, some possible elements of the lesson that impacted her engagement and performance were identified. Results from this case study indicate that problem posing for this student was an effective tool with which to evaluate misconceptions and to explore her informal mathematics understanding.
\end{abstract}

Keywords: case study, early childhood, mathematics, problem posing

\section{INTRODUCTION}

Problem posing is multifaceted in nature and structure. Problem posing requires that one must create problems. This is uniquely different from the traditional exercise of solving problems. In many classrooms across the United States (U.S.), problem posing is not ordinarily taught; nevertheless, the National Council of Teachers of Mathematics (2000) and the National Research Council (2005) have advocated the inclusion of problem posing in standard mathematics teaching strategies and curriculum. This support for incorporating problem posing in classrooms is centered on the documented constructive consequences of developing these skills. Findings from prior research have indicated that as students' problem-posing skills evolve, positive outcomes can be noticed in their creativity, understanding, problem solving, and critical thinking (Singer et al., 2015; Van Harpen and Presmeg, 2013). Moreover, problem posing can assist teachers in identifying mathematical misunderstandings (Koichu et al., 2013). Multiple benefits of integrating problem-posing activities in classrooms have been identified.

While problem posing is widely advocated, posing is not an end in itself but a means to attain improved mathematical understanding. Generally, when problems are presented in multiple formats, students are better able to acquire deeper understandings (Cai et al., 2013; Singer and Voica, 2012). When students can revise the problem itself, or design an analogous one, their understanding of the subtleties of the problem increases (Priest, 2009). Problem posing shifts the emphasis from attempting to uncover appropriate methods and derive correct answers in problem solving, to imaginatively posing a problem and then discovering the appropriate solution from a wide 
range of possibilities (Brown and Walter, 2005). An improvement in problem-solving skills is often observed as an outcome of engaging in problem-posing activities (Kar et al., 2010). Problem posing and solving can be two sides of the same coin - both pedagogies helping students develop mathematical understanding.

In addition to complementing and improving students' problem-solving skills, problem posing provides a creative space for teachers and students that is lacking or limited during the problem-solving process. While educators and teachers recognize the importance of using real-world scenarios when providing students with mathematical problems to solve, integrating authentic contexts into problems can be challenging. Problems based on real-world contexts are never true replications of real-world scenarios 'considering the infinite number of variables offered by real life problems' (Boaler, 1993, p.14). As every student understands and interprets problems they must solve differently, there is a need to integrate open-ended activities into mathematics classrooms that allow students to relate in-school and out-of-school mathematics experiences (Lowrie, 2004; Wright, 2017). Students may then realize that school mathematics and real-life mathematics are not disjoint entities. Teachers who implement problem-posing activities open a window of opportunity in which real-world scenarios and out-ofschool mathematics experiences derived from their students' lives can be incorporated into the problem space.

Although bringing real-world contexts into the math classroom maybe challenging, educators have recognized that students' out-of-school mathematics, or informal mathematical knowledge, can be used as a foundation for classroom instruction. A number sense has been observed to develop among children as early as infancy, with a rapid improvement in informal mathematical understanding thereafter (Resnick, 1989). However, children's informal mathematical understanding does not develop independently, but is influenced by their everyday lived experiences (Starkey and Klein, 2008). Therefore, students may benefit if educators base their curriculum on students' existing knowledge and experiences to formalize their knowledge and guide their understanding (Fennema et al., 1993). To this end, problem posing provides students with an opportunity to demonstrate and improve their mathematical knowledge, both formal and informal, in the mathematics classroom.

Problem posing allows the students to truly experience the essence of mathematical word problems. Instead of tasks with one right solution, problems in mathematics become 'opportunities to explore mathematics and come up with reasonable methods for solution' (Hiebert et al., 1997, p.8). The Common Core State Standards for Mathematical Practice \#1 require children to make sense of problems by justifying their answers while persevering in solving them (National Governors Association Center for Best Practices and Council of Chief State School Officers, 2010). Engagement with problems fosters motivation and long-term performance in mathematics (Furrer and Skinner, 2003). Thus, mathematical understanding and performance may be improved by student engagement in problem-posing activities.

Along with the numerous learning benefits for students, problem posing maybe used as an assessment tool by teachers. Research has shown that analyzing student work allowed teachers to gauge students' learning and thinking patterns (Lin and Leng, 2008). Problem-posing activities allow students to display the depth of their understanding of techniques and processes, which can provide teachers with an insightful assessment of their students' progress and current knowledge (Silver and Cai, 2005), while concurrently affording students a greater self-awareness of the extent of their mathematical understanding. Though problem posing can be used as an assessment tool, there is very limited research focusing on its efficacy as an informal assessment tool for teachers.

Using a single case study, the purpose of this study was to explore the possibility and effectiveness of adopting problem posing as an assessment tool to allow educators to understand students' mathematical strengths and weaknesses. Researchers in the present study investigated the role of problem-posing activities in understanding a second grader's mathematical understanding and reasoning.

\section{METHODOLOGY}

The structure for the larger study, approved through the Internal Research Board from the university, was a quasi-experimental design whereby the teachers of $2^{\text {nd }}-5^{\text {th }}$ grade classrooms each placed their students in heterogeneous groups organized by prior performance on the Texas STAAR test (high-stakes). All students participating in the study signed assent forms and their parents signed consent forms. Next, researchers who delivered the intervention were randomly appointed to a grade level in which they would administer the problemposing intervention; the researchers had no knowledge of the students or the teachers within their assigned intervention groups beforehand. The two authors of this manuscript were assigned to a second-grade classroom and received the following preparatory information and items before the study began: 1) instruction on both content and pedagogical methods for each problem-posing activity and 2) a folder containing lesson plans and materials for each of the problem-posing activities. 
European Journal of STEM Education, 2018, 3(2), 03

Table 1. Problem posing lessons conducted in the second-grade classroom

\begin{tabular}{rll}
\hline Sessions Topic & Description of lesson \\
\hline 1 & Pictures & Students wrote problems based on pictures provided \\
\hline 2 & Models & Students could choose one among manipulatives such as pattern blocks, unifix cubes and tokens. \\
\hline 3 & $\begin{array}{l}\text { Equation/number } \\
\text { sentence }\end{array}$ & Students wrote problems based on a number sentence \\
\hline 4 & Graphs & Wrote problems based on a given graph \\
\hline 5 & Geometry & Sorted pattern blocks by shape \\
\hline 6 & Graphs & Created a graph using a bag of M\&Ms \\
\hline 8 & Measurement & Traced out hand and measured length of their fingers \\
\hline 9 & Finance & Measured heights of characters in a picture \\
\hline
\end{tabular}

\section{Participants}

The current study was conducted in a rural school located in a small central Texas town with a population of 3000. The school (K-12) demographics included African American (31\%); Hispanic (25\%); and White (42\%). Of these students, $66 \%$ were categorized as economically disadvantaged. For this single case study, Paula (pseudonym) was selected as the research subject from a self-contained second-grade classroom of 28 students. Paula was a seven-year-old White female who lived within the rural community. She had one older brother, and her family qualified for free lunch. Paula showed improvement from pre- to post-testing, was present for all of the lessons, was actively engaged in the intervention, was fairly typical of the students in the second-grade classroom and was willing to justify her answers. For these reasons, the researchers selected this particular student's experience with the intervention to explore more deeply in order to determine what factors may have influenced the improvements in Paula's problem-posing abilities.

\section{Data Analysis}

Through the research design of this single case study (Kazdin, 1982), the researchers focused on one particular second-grade student. The following requirements for single subject designs were included: a) Continuous assessment - The mathematical reasoning of one individual second grader was observed over the course of the intervention, which was one semester. This ensured that any treatment effects were observed long enough to understand how the intervention affected the student's mathematical problem posing. b) Baseline assessment - Before the intervention was implemented, the researchers measured the student's mathematical problem-posing knowledge with a pretest and measured it again at the end of the semester. c) Variability in data - Because the one student's mathematical problem posing was observed repeatedly, the single subject design allowed the researchers to observe how consistently the intervention influenced her mathematical reasoning, as demonstrated through the change in her problem-posing skills over time. During the intervention, the student's work and researchers' observational notes were collected repeatedly throughout her completion of the weekly problem-posing activities. The student's work was evaluated for aspects of understanding and mathematical fluency.

\section{Classroom Milieu}

The $2^{\text {nd }}$ grade-level classroom contained learning centers. During the intervention period, one of the centers was led by the researchers, who facilitated student engagement in problem-posing activities that required students to create problems using real-world pictures, objects, or manipulatives. The researchers employed a variety of problem-posing strategies at this learning center during the intervention, all of which are outlined in Table 1. Two intervention activities were held each week for three months during the students' mathematics learning center time in the Spring 2017 Semester. Each activity lasted approximately 20 minutes. The researchers remained in the classroom for the entire mathematics period ( 90 minutes) and met with each group of students as they rotated through the learning centers during this time. At the other learning centers during the mathematics period, students practiced and reinforced skills that were introduced at the teacher instructional center through games, technology, and hands-on activities.

\section{Instrumentation}

A four-question quiz that included two problem-solving questions and two problem-posing questions (see Appendix for grade 2 level example) was administered to all participants. The pretest quiz measured problemsolving and problem-posing abilities at the beginning of the intervention (February 2017). Due to the inextricable link between problem solving and problem posing in previous literature, both types of questions were included on the quiz. An identical quiz was then administered to all participants in April, 2017 as a posttest. Each quiz was graded by two researchers to check for consistent and reliable scoring. 


\section{RESULTS \& DISCUSSION}

The second-grade mathematics teacher informed the researchers that she had never taught this group of second-grade students problem-posing strategies and had incorporated very few problem-posing activities into their instruction. She also reported that most of this cohort of students had great difficulty with posing their own problems. One student from this group, Paula, was the focus of the current study, and her problem-posing work was analyzed.

Over the span of the problem-posing intervention, Paula's ability to write and solve mathematics problems marginally improved as indicated by her improvement in problem-posing and problem-solving scores from pretest to posttest. For the first problem-posing question, which was based on a graph of books (see Appendix, Question 3), her pretest and posttest posed problems were as follows:

Pretest: "There was a book fair in the library on Wednesday and Saturday which one sold the books?"

Posttest: "Is there more Wednesday books sold than Friday?"

Similarly, for the second posing question (Question 4), Paula was asked to pose a problem based on a farm picture, to which she posed the following:

Pretest: "There whar [sic] 17 amnals in a barn and 3 came out because they ware [sic] too hot?"

Posttest: "Is there more chickens than hay bells [sic]?"

Unlike the pretest questions, both the posttest questions that she posed could be answered based on the accompanying graph or picture. In addition, Paula's focus shifted from providing details about the problem situation to constructing a problem statement. The change in focus may indicate an automatization of the problem scenario and problem-posing process in Paula's mind, therefore eliminating the need to re-iterate the description of the provided picture. This shift in focus, when applied to problem solving may help students streamline their thought process toward the problem statement. This change in focus may eliminate the need for rote methods such as highlighting the key words in a word problem to ascertain the mathematical operation required. An understanding of the problem structure may help Paula to better identify necessary and unnecessary information in a word problem.

Paula's ability to solve problems showed marginal improvement from pretest to posttest. On the first problemsolving question (Question 1), which required finding the difference between 25 and 17, Paula derived an incorrect answer on the pretest, but correctly solved the problem on the posttest. Her pretest setup for the problem was 17 -25 with a final answer of 12 . However, on the posttest she set the problem up and solved it correctly with a final solution of 8. On the second solving question (Question 2), Paula's performance from pretest to posttest was more nuanced than that of Question 1. Paula was asked to calculate based on a graph, how many more books were sold on Wednesday than on Thursday. Paula solved Question 2 correctly on the pretest; however, she appears to have misread the question on the posttest as she calculated the difference between books sold on Tuesday and Wednesday instead of books sold on Wednesday and Thursday. Although she could not derive the correct answer to the original problem due to her mistake, Paula nevertheless set up and correctly solved a problem of a relatively equal level of difficulty using the number of books sold on Tuesday and Wednesday.

While the pretest and posttest were used to measure both Paula's problem-posing and -solving performance, the researchers in the present study limited their primary analysis to Paula's problem-posing work over the course of the intervention. Constant comparison was used to investigate the non-linear gains found in Paula's problemposing performance to identify the similarities and differences in Paula's problem posing in an effort to understand the variance in her problem-posing performance among 9 lessons. First, some common errors made by Paula were identified, then her performance was analyzed in relation to the structure of the posing lesson.

Like many second graders, Paula occasionally struggled with creating a complete mathematical question. Her questions could be separated into those containing mathematical or non-mathematical errors. Errors were classified as mathematical if her question clearly indicated her intended mathematical operation but was incompletely worded. Non-mathematical errors were found in questions that did not contain or suggest the use of a specific mathematical operation.

\section{Non-mathematical Errors}

When Paula made a nonmathematical error while problem posing, it was most often in posing a problem that required an opinion, rather than a mathematic calculation. For example, during Lesson 5 Paula was given a bag of pattern blocks to sort by shape, and she created a bar graph using colors to represent the number of pieces she had in each shape. She then posed two questions, the second of which read, "My favit [sic] shape is rhombus?". Given that she had the highest number of rhombi compared to other shapes, her second statement might have been an attempt to ask, "Is my favorite shape a rhombus because I have the most of this shape?". However, there is no way one could mathematically infer her favorite shape (see Figure 1). 


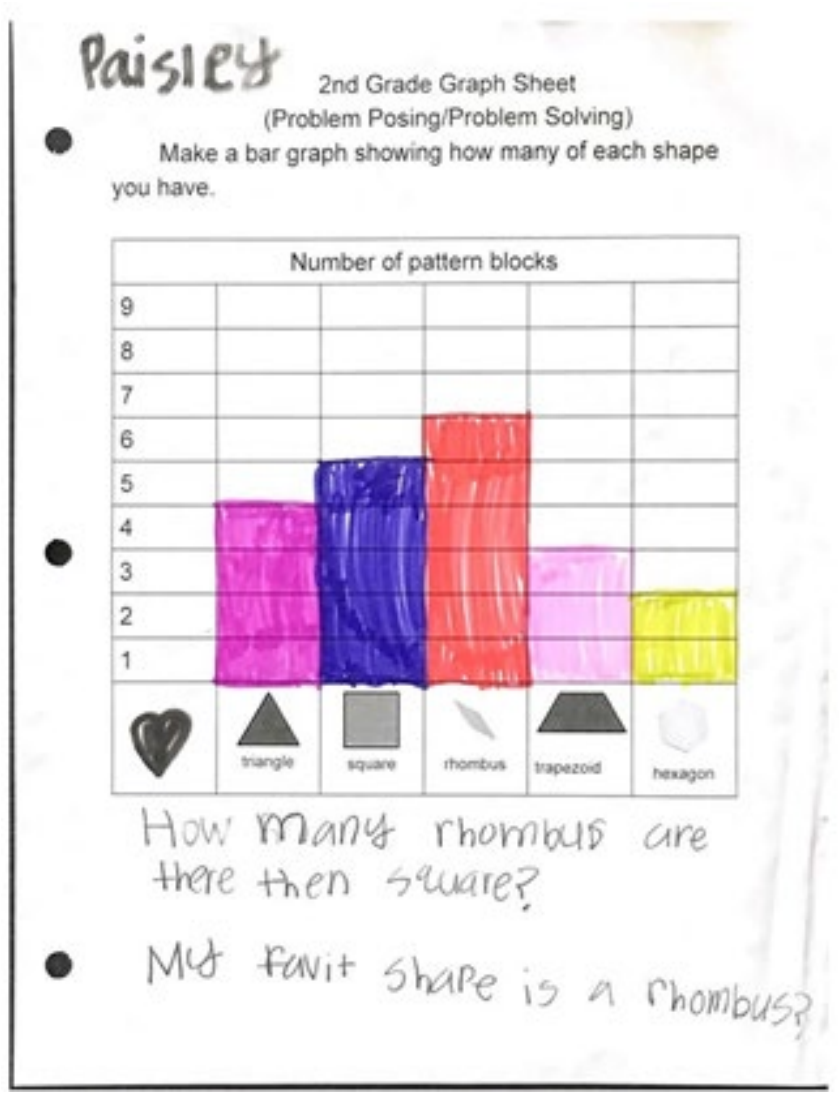

Figure 1. Paula's work for Lesson 5

Another error Paula made was providing a scenario with no question statement. When asked to write a problem based on a picture with farm animals, she wrote, "There whar [sic] 17 amnals[sic] in the barn and 3 came out because thay[sic] ware hot?". She immediately followed with setting up the solution as $17-3=$ ? . Paula assumed subtraction was a natural choice and replaced the lack of a question sentence with a question mark.

\section{Mathematical Errors}

Some of Paula's questions conveyed a mathematical question, but had words missing. When she wrote comparison problems, she omitted the words 'more' or 'less', leaving the reader to interpret the intent of the question. For example, in Lesson 5 (see Figure 1), Paula's first posed question was "How many rhombus [sic] are there then square [sic]?". In another example during Lesson 6 (sorting M\&Ms by color), her question read, "How many red than yellow?" instead of "How many more red M\&Ms are there than yellow?". Though the intent of these questions is easily interpretable, she needed to be reminded to include words such as 'more' or 'less' in her questions to make them complete. During the posttest, she was able to write complete and solvable questions.

While Paula practiced writing addition, subtraction, or comparison problems throughout the 9 lessons, her performance varied by the amount of mathematical abstraction. Specifically, when writing equations, Paula was able to successfully set up the solution for her posed problems in the form of an equation on multiple occasions. However, she had difficulty writing a problem when she was only given an equation. For an equation $9-3=$ she wrote an unrelated problem:

"So three hundred sixty-seven jelly been whar [sic] in a jar a boy gave me 200 now how many do I have now?".

This indicated a lack of cognitive flexibility in translating equation into a word.

Paula's performance during some lessons was independent of the mathematical content of the lesson itself. In other words, her performance on lessons that contained the same mathematical topic (e.g. measurement, graphs, etc.) varied depending on extraneous elements such as the context of the lesson or materials provided. Three possible artifacts of the lessons that may have impacted Paula's engagement and performance during the lessons were identified: 1) interaction with the materials, 2) relevance of the context, and 3) visual representation.

\section{Interactions with Materials}

Paula performed well when she could interact with materials (manipulatives). Physical objects or materials were an integral part of five of the nine lessons during the intervention. Paula was allowed to create her own scenario in Lesson 2 (using models); however, Lessons 5, 6, 7, and 9 (namely, categorizing shapes, creating a bar graph with $\mathrm{M} \& \mathrm{Ms}$, measuring finger length, and buying grocery items, respectively) each had a predefined context. In Lessons 


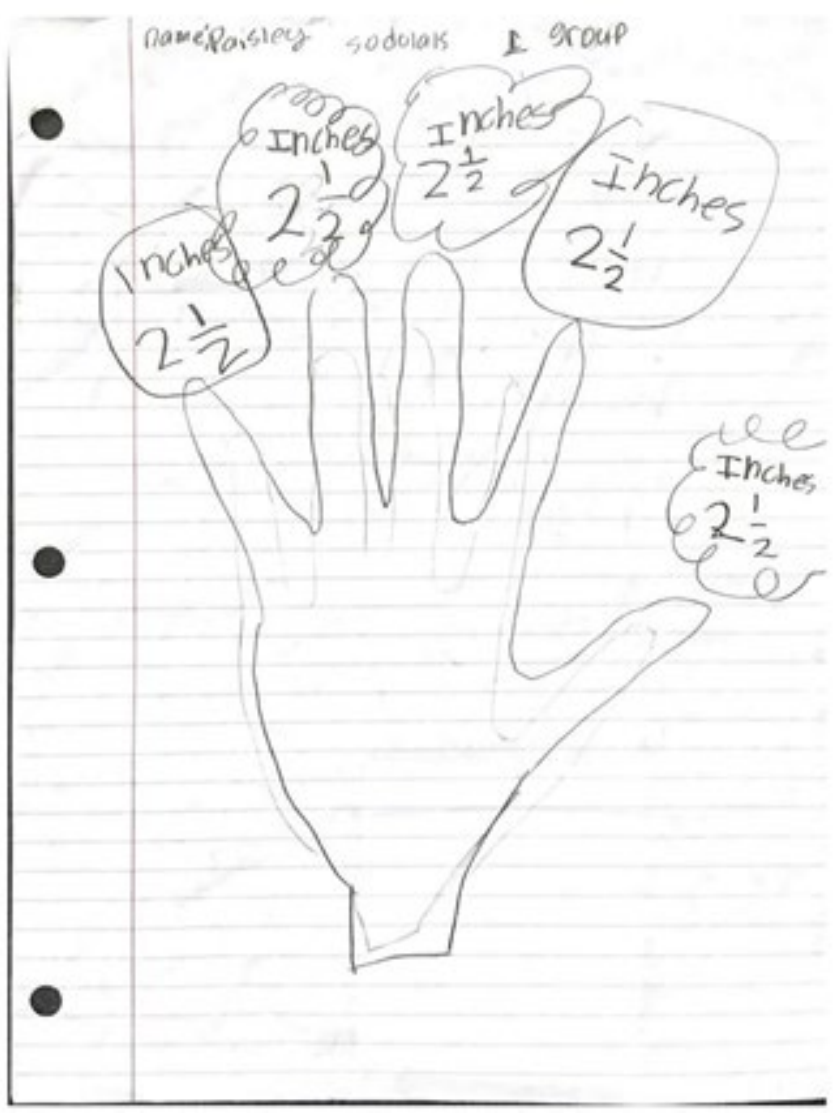

Figure 2. Paula's work for Lesson 7

5, 6 and 9, she was able to pose two to four problems during the 20-mintue activity, even after spending some of her time interacting with the materials. For Lesson 2, after posing one problem, she made an elaborate illustration of the scenario in the problem. These instances demonstrated her comfort with using the manipulatives to assist her in posing problems as a second grader.

However, not all hands-on activities seemed to be equally engaging for Paula. During Lesson 7, she was asked to trace out her palm and pose questions based on the measurements (see Figure 2). She wrote down the same length of $2 \frac{1}{2}$ inches for each finger. All four questions she posed were similar to "What is the length of my thum [sic] finger in inches?"; in posing the other three questions, Paula merely changed the name of the finger. Finding the answer required no mathematical calculation, unlike the other problems she had previously posed. While interaction with the materials helped Paula, the visual appeal and relevance of the materials impacted her enthusiasm.

\section{Relevance}

Paula seemed to be especially interested in topics that included animals. While she struggled with measuring her own traced palm, she performed better measuring the heights of animals in a picture of a popular children's movie, Jungle Book. She was able to measure 15 items in inches and write 4 problems each using a different operation such as counting, comparison, and addition. The difference between her performances with the hand measurement and animal measurement scenarios could indicate that the animal scenario was more interesting and relevant to her, thereby signifying that she exhibited her mathematical knowledge better when the scenario was relevant to her.

When the problem scenario contained animals, Paula was able to pose problems that contained multiplication, a concept beyond her grade level. In Lesson 1, when students were provided a pet shop picture, Paula wrote,

"So there were 12 pets in the pet store 3 people came and got two each how many are in the pet store now?".

In this problem, Paula was able to pose a problem that was solvable. Moreover, she extended her knowledge of addition to incorporate repeated addition. This posing response shows that Paula was familiar with repeated addition in an informal context and suggests that repeated addition could potentially be used as a tool to transition into teaching multiplication. 


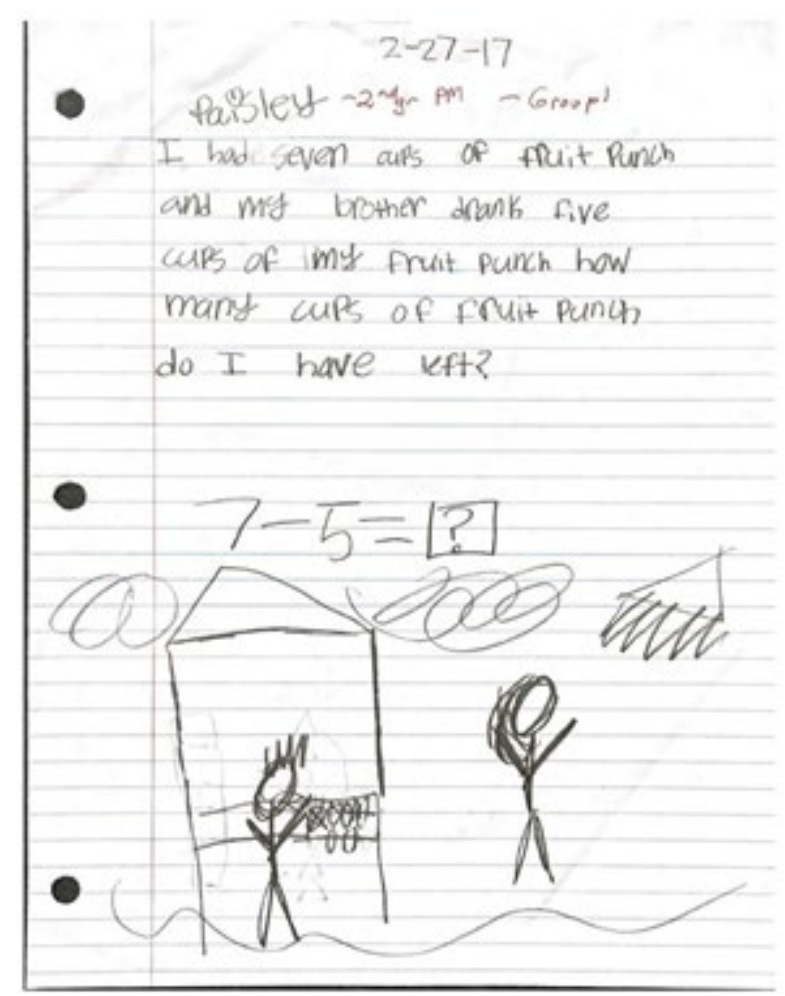

Figure 3. Paula's work for Lesson 2

\section{Visual Representations}

Paula displayed her enthusiasm and creativity while problem posing. Paula's work indicates that she appeared to have a vivid imagination that she used to create the scenarios that she included in her problems. Visual representations appeared to stimulate and aide her imagination. Paula compensated for the lack of mathematical structure, which she frequently used to guide her problem-posing process, by relying on her imagination and ability to visually represent and justify her imagination. This tactic appeared to help her better process abstract mathematic problem scenarios whose information she had to understand in order to pose her own problems. For example, in Lesson 2, she used models of her own making to help her write a real-world problem about her and her brother (see Figure 3).

Paula consistently seemed to enjoy visuals that accompanied the problem scenarios she was required to use when problem posing. She may have been more receptive to pictures as content in elementary grades is usually accompanied by visuals. Paula, like most second graders, was excited to pose problems using a picture of a popular cartoon character, Spongebob. After a discussion about the objects in the picture, such as patties, buns, and barrels, she wrote,

"Sponge Bob grilled 13 burgers and he burned 3 by accident, how many could he sell that were not burnt?".

Similarly, visual stimuli like graphs enabled Paula to construct a fairly complicated problem:

"There is 35 girls at the swimming pool then 35 boys came to the pool how many boys and girls are there now? There are 15 girls and 20 boys at canoeing? How many more kids are at the pool than canoeing?".

Thus these visuals clues especially related to a familiar context were helpful when Paula, as a second grader, began her problem posing journey.

\section{CONCLUSIONS}

A majority of the current teaching and evaluation methods in elementary classrooms are directed toward solving problems. While efforts are made to integrate real-world scenarios into problem solving, a disconnect between inschool and out-of-school mathematics is often evident (Boaler, 1993). This gap between real-life and school mathematics may be bridged with open-ended activities such as problem posing. While problem solving usually has a binary outcome of correct or wrong, problem posing provides students with an opportunity to explore a plethora of mathematical scenarios.

During the intervention focused on problem posing, Paula displayed marginal improvements in her problemsolving skills as was substantiated by prior researchers (Cai et al., 2013; Kar et al., 2010). More importantly, Paula's problem-posing responses were helpful in informally assessing her thought processes, understandings, and 
performance. As suggested in prior research (e.g., Koichu et al., 2013), through these brief informal assessments Paula's error patterns and problem areas could be identified based on her problem-posing work. Her posing responses helped identify errors directly related to the mathematical topic at hand, as well as general mathematical misconceptions. Paula was more likely to display her understanding of mathematics concepts when she was physically engaged or was given a scenario that sparked her imagination. For example, when provided the visual of the pet shop, Paula was able to formulate and justify complex multi-step problems and extend her mathematical knowledge. Paula was able to pose a "multiplication problem" even though she was never exposed to the concept multiplication in her second-grade classroom. In contrast, she had trouble with mathematical abstraction, which she sometimes compensated for by using visuals or manipulatives. Exposure to problem-posing activities provided Paula with a picture of the inverse of solving problems. Problem posing may be used not only as a means to evaluate student misconceptions, but also to explore their informal mathematics understanding. Educators should assess and utilize students' familiarity with higher level math concepts, acquired through real-life experiences, as a tool and bridge that may be used to formally introduce concepts in school.

The focus of the current study was to explore the viability of using problem posing to understand the mathematical profile of a second grader through seamless informal assessments. A single case study was the most suitable method for an in-depth analysis of posing responses. Furthermore, the current method of analysis is likely most applicable when seeking to understand the mathematical profile of individual students. However, creating a detailed portrait of every student in the classroom may be neither practical nor feasible due to factors teachers encounter that place constraints on their instructional choices, such as limited time during a class period. Therefore, the portraiture scope in many cases should be modified. Rather than aiming to derive a mathematical portrait of each student through the incorporation of problem-posing activities, teachers should strive to sketch a mathematical 'class portrait' from which they may begin identifying subgroups of students in their classes that require intervention and specialized assistance in particular mathematical areas of weakness (e.g., multiplication of whole numbers, equivalent fractions, division into equal groups). This use of problem-posing is a feasible and more flexible alternative to individual assessment, and its use may assist teachers in targeting specific deficiencies in their students' mathematics performance. In addition, continued use of problem-posing activities within the identified subgroups will help these students to initiate mathematical dialogue, which teachers can guide and evaluate to determine their students' progress and identify their misconceptions, informal understanding, thought processes, and learning patterns (Lin and Leng, 2008) in relation to their identified mathematical deficiencies. In sum, there are benefits to creating 'mathematical portraits' of individual students as well as 'collective mathematical portraits' through which educators can identify subgroups lacking or deficient in specific mathematics skill sets, and the use of both may assist educators in identifying their students' mathematical deficiencies and improving their overall mathematical understanding and performance.

\section{REFERENCES}

Boaler, J. (1993). The role of contexts in the mathematics classroom: Do they make mathematics more" real"? For the Learning of Mathematics, 13(2), 12-17.

Brown, S. I. and Walter, M. I. (2005). The art of problem posing (3rd ed.). Hillsdale, NJ: Erlbaum.

Cai, J., Moyer, J. C., Wang, N., Hwang, S., Bie, B. and Garber, T. (2013). Mathematical problem posing as a measure of curricular effect on students' learning. Educational Studies in Mathematics, 83, 57-69. https://doi.org/10.1007/s10649-012-9429-3

Fennema, E., Franke, M. L., Carpenter, T. P. and Carey, D. A. (1993). Using children's mathematical knowledge in instruction. American educational research journal, 30(3), 555-583. https:// doi.org/10.3102/00028312030003555

Furrer, C. and Skinner, E. (2003). Sense of relatedness as a factor in children's academic engagement and performance. Journal of Educational Psychology, 95(1), 148. https://doi.org/10.1037/0022-0663.95.1.148

Hiebert, J., Carpenter, T. P., Fennema, E., Fuson, K., Wearne, D., Murray, H., Oliver, A. and Human, P. (1997). Making sense: Teaching and learning mathematics with understanding. Portsmouth, NH: Heinemann.

Kar, T., Özdemir, E., İpek, A. S. and Albayrak, M. (2010). The relation between the problem posing and problem solving skills of prospective elementary mathematics teachers. Procedia-Social and Behavioral Sciences, 2(2), 1577 1583. https://doi.org/10.1016/j.sbspro.2010.03.239

Kazdin, A. E. (1982). Single-case research designs: methods for clinical and applied settings. New York, NY: Oxford University Press.

Koichu, B., Harel, G. and Manaster, A. (2013). Ways of thinking associated with mathematics teachers' problem posing in the context of division of fractions. Instructional Science, 41(4), 681-698. https://doi.org/10.1007/s11251-012-9254-1

Lin, K. M. and Leng, L. W. (2008). Using problem-posing as an assessment tool. In 10th Asia-Pacific Conference on Giftedness, Singapore. 
Lowrie, T. (2004). Making mathematics meaningful, realistic and personalised: Changing. Available at: https://www.mav.vic.edu.au/files/conferences/2004/Lowrie.pdf

National Council of Teachers of Mathematics. (2000). Principles and standards for school mathematics. Reston, VA: Author.

National Governors Association Center for Best Practices \& Council of Chief State School Officers. (2010). Common Core State Standards for Mathematics. Available at: http:/ /www.corestandards.org/Math/

National Research Council. (2005). How students learn: History, mathematics, and science in the classroom. Washington, DC: Division of Behavioral and Social Sciences and Education, National Research Council of the National Academies.

Priest, D. J. (2009). A problem-posing intervention in the development of problem-solving competence of underacbieving, middle-year students (Doctoral dissertation, Queensland University of Technology, Brisbane, Australia).

Resnick, L. B. (1989). Developing mathematical knowledge. American Psychologist, 44(2), 162-169. https://doi.org/10.1037/0003-066X.44.2.162

Singer, F. M., Ellerton, F. and Cai, J. (2015). Mathematical problem posing. New York, NY: Springer. https://doi.org/10.1007/978-1-4614-6258-3

Singer, F. and Voica, C. (2012). A problem-solving conceptual framework and its implications in designing problem-posing tasks. Educational Studies in Mathematics, 83(1), 9-26. https:// doi.org/10.1007/s10649-012-9422$\mathrm{x}$

Silver, E. and Cai, J. (2005). Assessing students' mathematical problem posing. Teaching Children Mathematics, 12(3), 129- 135.

Starkey, P. and Klein, A. (2008). Sociocultural influences on young children's mathematical knowledge. In O. N. Saracho \& B. Spodek (Eds.), Contemporary perspectives on mathematics in early childhood education (pp. 253-276). Charlotte, NC: Information Age Publishing.

Van Harpen, X. Y. and Presmeg, N. C. (2013). An investigation of relationships between students' mathematical problem-posing abilities and their mathematical content knowledge. Educational Studies in Mathematics, 83(1), 117-132. https://doi.org/10.1007/s10649-012-9456-0

Wright, P. (2017). Critical relationships between teachers and learners of school mathematics. Pedagogy, Culture \& Society, 25(4), 515-530. https://doi.org/10.1080/14681366.2017.1285345

\section{APPENDIX}

\section{Pre/Post Test (2nd Grade)}

1. Wendy spent $\$ 17$ on a DVD. If she gave $\$ 25$ to the cashier, how much change did she get back? Be sure to show your work.

\begin{tabular}{|c|c|}
\hline Days & Books sold \\
\hline Monday & $\theta \theta$ \\
\hline Tuesday & Q \\
\hline Wednestay & e] \\
\hline Thursday & ] \\
\hline Friday & a) \\
\hline Saturday & $\theta 0 \theta 00$ \\
\hline
\end{tabular}

2. Using the pictograph above, how many more books were sold on Wednesday than on Thursday? Be sure to show your work. 


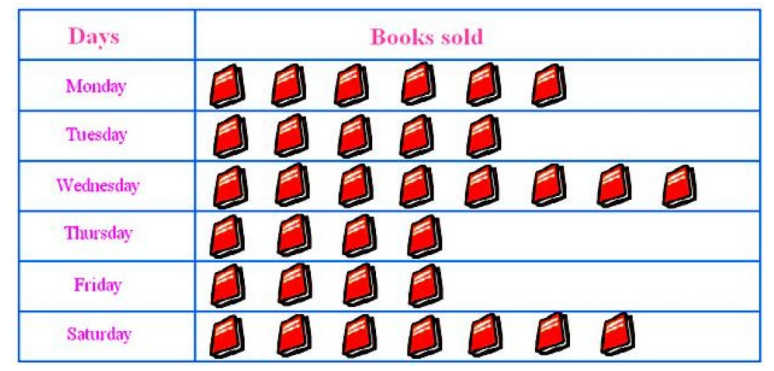

3. Using the pictograph above, create an addition word problem for a friend to solve. Set your problem up, but you do NOT have to solve it.

$\underline{\text { Problem }}$

\section{$\underline{\text { Setup }}$}

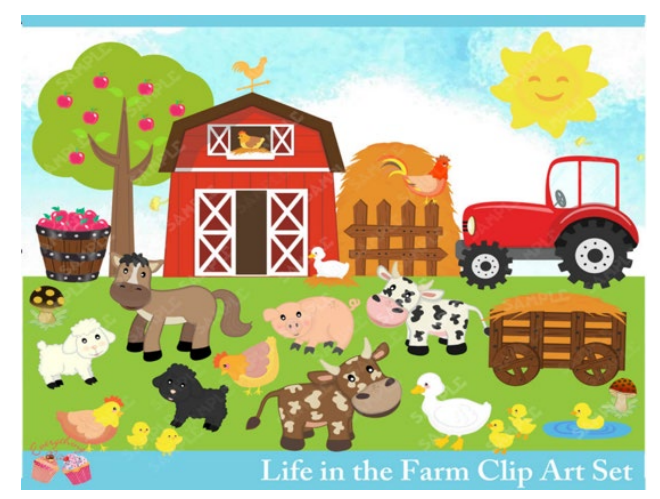

4. Using the farm picture, create a word problem for a friend to solve. Set your problem up, but you do NOT have to solve it.

Problem

$\underline{\text { Setup }}$ 